\title{
O LÉXICO AVALIATIVO-PORTUGUÊS: UMA PERSPECTIVA PARADIGMÁTICA COM BASE NA LINGUÍSTICA SISTÊMICO-FUNCIONAL
}

\author{
Alex Luis dos Santos (UFMG)
}

Cláudio Márcio do Carmo (UFSJ)

Resumo: A referência à realidade extralinguística nos discursos humanos faz-se pelos signos linguísticos, ou unidades lexicais, que designam os elementos desse universo, inclusive as polêmicas sociais. Uma dessas polêmicas está retratada no texto Carta Circular para ajudar as conferências episcopais na preparação de linhas diretrizes no tratamento dos casos de abuso sexual contra menores por parte de clérigos. Esse texto faz parte d'A resposta da Igreja que avalia o envolvimento de clérigos católicos em casos de pedofilia.

O que se busca neste artigo, então, são a identificação, o resumo e a interpretação das instâncias léxico-avaliativas que apontam o posicionamento afetivo, ético e estético, a fim de se discutir como essas instâncias são capazes de construir o posicionamento atitudinal do produtor textual. A conclusão a que se chega com base nas lexias identificadas é a de que o produtor do texto advoga e arquiteta discursivamente a lidimidade do clérigo em suspeita e, por conseguinte, o despudor dos delatores.

Palavras-chave: Léxico, Avaliação, Abuso sexual.

Abstract: The reference to extralinguistic reality in human discourse is done by linguistic signs, or lexical units that designate elements of this universe, including social controversies. One such controversy is portrayed in the text Carta Circular para ajudar as conferencias episcopais na preparação de linhas diretrizes no tratamento dos casos de abuso sexual contra menores por parte de clérigos. This text is part of The Church's response that evaluates the involvement of Catholic clergy in cases of pedophilia.

What is sought in this paper, then, is the identification, summary and interpretation of lexical-evaluative instances that link the affective, ethical and aesthetic positioning, in order to discuss how these instances are able to construct the attitudinal position of the textual producer.The 
conclusion that is reached by the identified lexias is that the producer of the text advocates and architects discursively legitimacy Clergyman in suspicion and therefore the shamelessness of informers.

Key-words: Lexicon, Evaluation, Sexual abuse.

\section{INTRODUÇÃO}

As recentes divulgações pelos canais de imprensa do envolvimento, por vezes evidenciado, de clérigos da Igreja Católica em casos de abusos sexuais contra menores desenvolveu um intenso debate sobre os procedimentos aplicados pela instituição para o julgamento dos envolvidos.

Nesse contexto, a Carta Circular para ajudar as conferências episcopais na preparação de linhas diretrizes no tratamento dos casos de abuso sexual contra menores por parte de clérigos constitui um dos textos publicados pela Santa Sé no que a instituição denomina $A$ resposta da Igreja.

Tal resposta implica, consoante o título supracitado e o produtor do texto - William Cardinale Levada - o estabelecimento de procedimentos capazes de dar assistência às vítimas de abusos sexuais, bem como a formação da comunidade eclesial com vistas à proteção dos menores.

Para tanto, no texto de Levada o autor lança mão de um conjunto de unidades léxico-avaliativas capazes de construir uma perspectiva sobre o envolvimento clerical nos casos de 
abusos contra menores a partir de um universo semântico existente. Para Biderman (2001a, p.179), "ao fim e ao cabo, o universo semântico se estrutura em torno de dois polos opostos: o indivíduo e a sociedade. Dessa tensão em movimento se origina o léxico".

Destarte, o que este trabalho realiza é uma investigação da relação entre léxico e avaliação no texto Carta Circular para ajudar as conferências episcopais na preparação de linhas diretrizes no tratamento dos casos de abuso sexual contra menores por parte de clérigos.

A análise desse material é justificada do ponto de vista da avaliação na linguagem por dois importantes argumentos. O primeiro diz respeito à contribuição científica prestada às aplicações ainda incipientes do sistema de avaliatividade no Brasil. Trata-se de uma proposta teórica que, com amplo escopo de aplicação, ainda carece de trabalhos que divulguem seu potencial em descrever relações entre os recursos léxicoavaliativos utilizados por agentes sociais e aspectos da rede de práticas em que a interação discursiva se insere.

O segundo, contíguo ao primeiro, reside no fato de que a investigação está interessada nas funções sociais dos recursos de atitude, não simplesmente como formas através das quais o produtor expressa seus sentimentos 
e postura. Está interessada também numa concepção de atitude enquanto meios que permitem que o produtor adote posições de valor determinadas socialmente, e assim se filie, ou se distancie das comunidades de interesse associadas ao contexto comunicacional em questão, o que parece uma abordagem profícua.

Sendo assim, objetiva-se a identificação, o resumo e a interpretação das instâncias léxico-avaliativas que apontam o posicionamento afetivo, ético e estético, a fim de se discutir como essas instâncias são capazes de construir o posicionamento atitudinal do produtor textual.

Dentro dos níveis metodológicos nos quais a trabalho pode se basear, sugeridos por Ikeda e Vian Júnior (2006, p.37-43), o estudo se enquadra na análise lexical, isto é, no estudo da "forma de registrar o conhecimento do universo" (BIDERMAN, 2001, p.13). Portanto, para o exame desse nível adota-se a proposta de Eggins e Slade (1997, p.138) que consiste em identificar as instâncias léxico-avaliativas, classificá-las e resumi-las, e, finalmente, interpretá-las com vistas ao contexto de produção a que pertencem.

A organização do trabalho para que se favoreça a compreensão e harmonia entre as seções que o integram se dá conforme o seguinte: exposição do arcabouço teórico, 
em que se focaliza o significado atitudinal dentro do sistema de avaliatividade, a discussão dos dados, consoante à metodologia supracitada, as considerações finais e as referências bibliográficas.

\section{COMPREENDENDO O SISTEMA DE AVALIATIVIDADE (APPRAISAL SYSTEM)}

O termo "avaliação" é, segundo Susan Hunston e Geoff Thompson (2003, p.5), reconhecidamente escorregadio dentro dos estudos linguísticos de que em geral faz parte: há uma tradição bem estabelecida na análise do discurso de usá-lo para se referir a elementos de padrões textuais (cf. HOEY, 1983). Por vezes, também é utilizado em um sentido mais restrito na análise de expressões lexicais da atitude emocional do escritor ou falante (cf. CARTER, 1987), o que mais ou menos equivale à ideia de Martin e White (2005).

Para Hunston e Thompson (2003, idem), com base em Georgakopoulou e Goutsos (1997), a avaliação (evaluation) é um conceito complexo que envolve as expressões de atitude ou postura do falante ou escritor que por meio delas demonstra um ponto de vista ou um sentimento sobre entidades ou proposições. Segundo Martin e White, Hunston e Thompson distinguem pareceres sobre entidades e sobre proposições. Opiniões sobre,

entidades são canonicamente atitudinais e envolvem pensamentos positivos e 
negativos; opiniões sobre proposições, por outro lado, são canonicamente epistêmicos e envolvem graus de certezas (MARTIN; WHITE, 2005, p.38).

O primeiro tende a ser feito lexicalmente e o último gramaticalmente.

Diferentemente de Hunston e Thompson, Martin e White (2005), cujo trabalho consubstancia grande parte do que foi desenvolvido a partir da década de 80 sobre a avaliação no discurso, apresenta tipos e subtipos de atitudes que abrangem o processo avaliativo. Esse processo é apresentado sobre a rubrica appraisal (avaliatividade) e refere-se, de acordo com Martin e White (2003, p.145) aos recursos semânticos usados para negociar emoções, julgamentos e valorações, junto dos recursos requeridos para ampliar e engajar essas avaliações.

O sistema de avaliatividade (appraisal system), assim denominado e entendido, considera um potencial de significados avaliativos disponíveis no sistema linguístico. Desse modo, envolve por conseguinte questões relacionadas à filogênese e à ontogênese para que o nível logogenético se desenvolva em termos de funcionamento linguístico (VIAN JUNIOR, 2007, p.103).

Em termos mais acessíveis, isso significa, consoante Martin e White (2005), que uma cultura, referindo-se ao ambiente 
político-social que dá o propósito e o significado ao texto ${ }^{1}$, em estado de evolução (filogênese) prevê um contexto social para o desenvolvimento linguístico do indivíduo (ontogênese). Ao ponto que o indivíduo que se encontra no seu desenvolvimento prevê recursos para a instanciação ${ }^{2}$ de desdobramentos de textos (logogênese). As mudanças na língua são vistas, nessa perspectiva, como expansões de um significado potencial, uma característica-chave dos sistemas semióticos e, portanto, dos mecanismos avaliativos que se adaptam aos novos ambientes e ao material discursivo.

No sistema de avaliatividade, esses mecanismos avaliativos obedecem a três domínios interacionais: a atitude, o engajamento e a gradação. O fenômeno da gradação refere-se à utilização de recursos léxico-gramaticais para expressar e ajustar o grau, ou o volume da intensidade das avaliações de julgamento, afeto e apreciação -disponíveis no domínio da atitude- e o volume da intensidade dos recursos de posicionamento intersubjetivo- disponíveis no domínio do engajamento. O engajamento localiza-se no eixo das

1 Essa perspectiva sobre cultura está ancorada, inicialmente, nos trabalhos desenvolvidos pelo antropólogo Bronislaw Malinowski (1923). No entanto, para servir aos estudos linguísticos, especificamente ao arcabouço teórico da Linguística Sistêmico-Funcional- Halliday (1994) especialmente, a compreensão de Malinowski foi complementada e adaptada por Firth (1957).

2 A noção de instanciação é de extrema importância para que se compreenda a relação entre avaliatividade (no nível do sistema) e avaliação (no nível do texto), isto é: o sistema linguístico é instanciado em forma de texto. Independentemente do tipo de texto que se produza, do mais corriqueiro bom-dia a uma tese científica, ou dos valores inerentes a tais textos, qualquer um deles será uma instanciação de um sistema mais amplo. 
negociações. O ponto de partida envolve um enfoque no direcionamento das vozes que se encontram no texto: de onde/quem partem e para onde/quem se dirigem e, mais importante que isso: quais vozes avaliam e quais são avaliadas.

O domínio da atitude ocupa um lugar central no processo avaliativo, já que revela os tipos e níveis em que a avaliatividade é desenvolvida e expressa no discurso. Conforme Martin e Rose (2003, p.22), a atitude tem a ver com a avaliação das coisas, com o caráter das pessoas e com seus sentimentos. Isso significa que esse domínio abrange três regiões semânticas: a emoção, a ética e a estética.

Cada região semântica envolve sentimentos ${ }^{3}$ e corresponde respectivamente às denominações afeto, julgamento e apreciação. Todavia, o julgamento e a apreciação são, conforme avisam Martin e White (2005), disposições desses mesmos sentimentos que são institucionalizados para que os falantes ou escritores possam entrar nas comunidades uns dos outros. Subsume-se, consequentemente, que, ao avaliar o comportamento das pessoas ou os objetos e entidades concretos com as quais se depara, o falante/escritor ativa

3 Cabe nesse ponto esclarecer o que se entende por essa entrada. O uso que Martin e White (2005) faz desse termo é propínqua à concepção de Damasio (1994), quando este elabora a distinção entre 'emoção' e 'sentimento'. Damasio define a emoção como mudanças no estado sensorial, o que significa alteração no comportamento, em resposta às situações positivas e negativas. A percepção desse comportamento que se manifesta é, logo, tratada como um sentimento. 
necessariamente uma série de valores culturais e específicos de comunidades sociais que com eles se identificam.

Nesse sentido, o léxico de uma língua é de suma importância, uma vez que, segundo Biderman (1996, p.27)

a referência à realidade extralinguística nos discursos humanos faz-se pelos signos linguísticos, ou unidades lexicais, que designam os elementos desse universo segundo o recorte feito pela língua e pela cultura correlata.

A relação entre as regiões semânticas está representada na forma diagramática abaixo que apresenta a centralidade do afeto no domínio atitudinal.

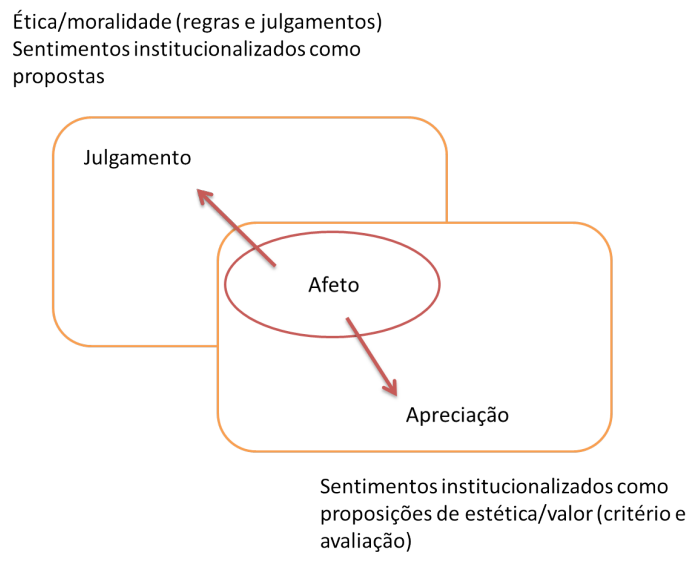

Figura 1: Julgamento e apreciação como afeto institucionalizado [adaptado de Martin e White $\left(2005\right.$, p.45) ${ }^{4}$ ]

4 Ao propor, dentro da forma diagramática, o julgamento como sentimentos institucionalizados, como propostas, e a apreciação como sentimentos institucionalizados como proposições, os autores tomam a ideia de "proposta" enquanto normas que indicam o modo pelos quais as pessoas devem ou não se comportar e "proposições" enquanto pontos de vistas que devem ser tomados como aceitáveis, melhores sobre aquilo que se avalia. 
Enquanto um recurso semântico utilizado para realizar as emoções, o afeto diz respeito às avaliações pautadas nos sentimentos dos falantes/escritores indicando como se comportam emocionalmente em relação às pessoas, às coisas, aos objetos e aos acontecimentos (MARTIN, 2003, p.148). Trata-se do registro desses sentimentos que podem ser positivos ou negativos: sente-se feliz ou triste; confiante ou ansioso, interessado ou entediado. As características do afeto indicam que as pessoas possuem bons e maus sentimentos que são manifestados de forma explícita ou implícita ${ }^{5}$.

Macken-Horarik (2003, p.298) lembra que a avaliação implícita, de qualquer tipo, é identificada através de certo tipo de enriquecimento lexical, o que significa uma sutil inferência ou uma linguagem figurada. Martin (2003) prefere chamar essa forma de avaliação como tokens de atitude. Para este autor, tais avaliações são mais difíceis de detectar, uma vez que seu significado é transferido e não literal. Ikeda complementa esse raciocínio ao precisar:

A interpretação de tipos de Appraisal evocados depende pesadamente das inferências feitas pela audiência do texto. Como todas as análises de Appraisal, a classificação dessas

5 Quando as avaliações são realizadas diretamente no texto, ou seja, quando é codificado um valor positivo ou negativo que pode ser intensificado para mais ou para menos, são consideradas explícitas. Já quando as avaliações são consideradas indiretas, implicadas ou sugerem uma interpretação do ouvinte/leitor, elas são implícitas. 
evocações envolve um grau de subjetividade e precisa ser entendida como situadas em contextos culturais específicos. Por isso, essas instâncias de Appraisal podem ter múltiplas interpretações (IKEDA, 2006, p.1881).

Já em relação ao julgamento, pode-se dizer que esse recurso constrói linguisticamente as avaliações do comportamento das pessoas. Ele traduz a maneira pela qual as pessoas realizam suas opiniões sobre moralidade, legalidade, capacidade, normalidade sempre determinados pela cultura na qual vivem e pelas experiências, expectativas, pretensões e crenças individuais.

O terceiro e último recurso semântico da atitude é a apreciação. Por meio dela são construídas as avaliações sobre coisas, objetos e fenômenos. Esse recurso é considerado por Eggins e Slade (1997, p.125) um importante expediente atitudinal disponível, uma vez que se refere ao modo pelo qual os falantes/escritores avaliam o texto (oral ou escrito) ou o processo (algum evento).

\section{ANÁLISE DOS DADOS}

O mapeamento das instâncias atitudinais satisfaz primariamente à função de percepção e descrição do modo como o produtor articula linguisticamente a opinião no discurso que produz. Essa etapa coaduna a identificação 
e o resumo das formas léxico-avaliativas previstas por Eggins e Slade (1997) para o exame do posicionamento assumido pelo falante/escritor no processo de avaliação. É profícuo à medida que cumpre neste trabalho o propósito de investigação da maneira como os significados foram engendrados por William Cardinale Levada, quem responde sobre a carta circular- objeto de análise.

Assim, o gráfico 1 sumariza o cômputo e os tipos de lexias atitudinais responsáveis pela expressão linguística das avaliações positivas e negativas que abrangem a emoção, a ética e a estética. Por lexias entendem-se as unidades léxicas variáveis de uma língua. A observação das modalidades de lexias atitudinais, com base em Martin e White (2005), encontra-se no gráfico disposta em porcentagem. 


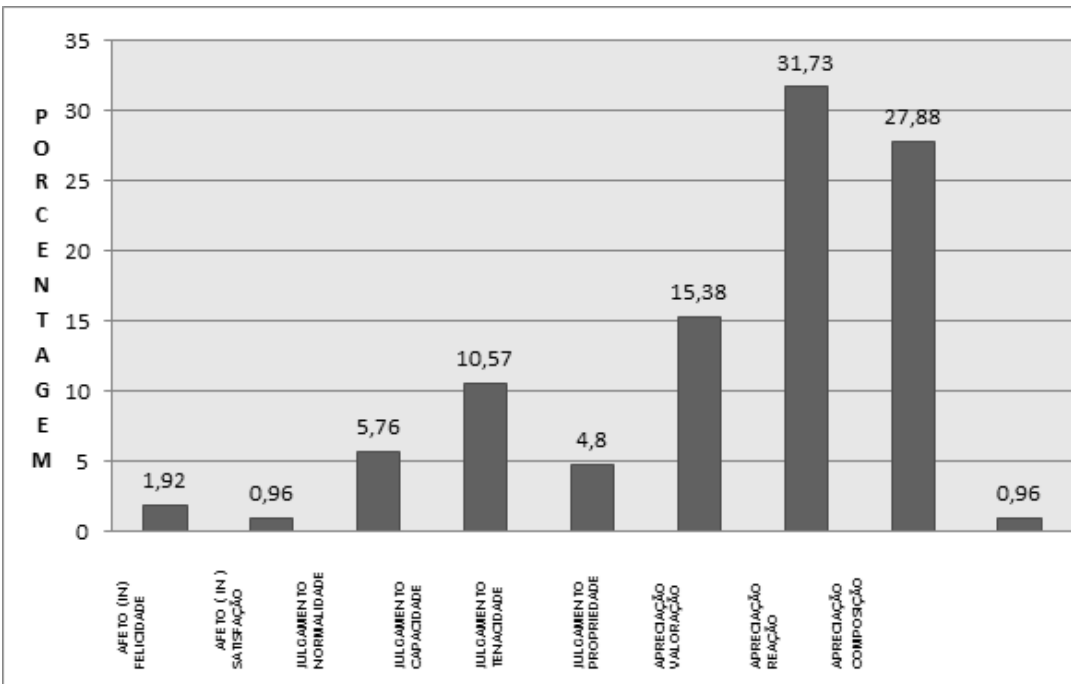

Gráfico 1: Cômputo dos tipos de lexias atitudinais

As instâncias avaliativas do tipo apreciação/valoração e apreciação/reação demonstram, com base na predominância de suas ocorrências léxicas, a preocupação do produtor em recontextualizar o valor de algum fenômeno semiótico ou material dentro de um determinado campo, situação ou cultura, uma vez que a apreciação traduz sentimentos institucionalizados e representados como qualidades positivas ou negativas.

Martin e Rose (2003, p.37) afirmam que a apreciação diz respeito, entre outras coisas, às avaliações sobre objetos, performances de qualquer tipo, estados de coisas e relacionamentos. Os fenômenos/objetos da apreciação do 
produtor sinalizam maiormente, a exemplo de (A) e (B), a postura da Igreja a ser tomada no tratamento dos casos de abuso sexual por parte de clérigos e as ações ou programas já implantados para esse tratamento.

(A) A Igreja, na pessoa do Bispo ou de um seu delegado, deve se mostrar pronta para ouvir as vítimas e os seus familiares e para se empenhar na sua assistência espiritual e psicológica.

(B) Os supracitados programas mereceram amiúde um reconhecimento como modelos na luta para eliminar os casos de abuso sexual contra menores nas sociedades hodiernas.

Eggins e Slade (1997, p.127), ao resumirem as formas léxico-gramaticais que podem ser utilizadas para realizar a apreciação admitem a possibilidade de predicadores - como em (A) onde de se utiliza verbos funcionando como instâncias de apreciação- e de formas nominais como em (B). Martin e White (2005, p.58) assinalam que avaliações positivas e negativas de alguma coisa implicam em julgamentos positivos e negativos sobre a capacidade de alguém criar ou realizar. Essa propriedade dos valores de apreciação subsume, portanto, a avaliação sobre o comportamento humano, o que significa uma maneira implícita de realização do julgamento. 
Desse modo, em (A) ocorre a apreciação/valoração/ relevância com implicações de julgamento/capacidade. A valoração é relatada por Martin e White $(2005$, p.57) como opiniões consideradas em relação ao tipo de processo mental identificado como cognição (entender, refletir) e à metafunção ideacional da linguagem. Para Halliday (1994, p.106) a metafunção ideacional ou experiencial trata do uso da língua como representação, servindo para manifestações sobre o mundo, destacando como ele é percebido, sentido, experienciado e representado, principalmente por meio de unidades léxicas.

Destarte, o produtor assume como importante e exemplar - a relevância tem essa finalidade - e isto pressupõe a resolução da Igreja, por conseguinte, dos clérigos de certos escalões, em assistir, espiritual e psicologicamente, as vítimas de abuso sexual. A assistência psicológica a que se refere o produtor é reconhecida no trabalho de MacArthur e Mack (1994), para os quais, nos últimos anos, o que se tem observado entre as igrejas cristãs é a recorrência de uma psicologia secular coberta com terminologia espiritual. A esse respeito, Collins discute a utilização da bíblia por clérigos para ensinamentos de psicologia humana: 
A despeito da riqueza de informações sobre os seres humanos, seu universo e seu Deus, a Bíblia não foi criada para ser um livro de texto de psicologia (...) É claro, a Bíblia não nos fala sobre questões como a base biológica da depressão, o efeito da empatia, o prejuízo ao longo da vida causado por abuso emocional ou físico, o meio pelo qual as pessoas aprendem, os estágios de desenvolvimento da infância, os pontos de resolução de conflitos, ou os meios de tratar a dislexia e a paranóia. A psicologia sim, se concentra em questões como essas ${ }^{6}$ (COLLINS, 2000, p.110, grifo nosso).

Qual for a posição que se adote nessa discussão, importa observar o lugar que se constrói e afirma para o clérigo como o que assiste, tranquiliza e apascenta; não aquele que coage e abusa. Esta afirmação de um lugar social estimado se manifesta, segundo Habermas (1983, p.78), sobretudo, em situações críticas, quando uma pessoa é confrontada com exigências ou situações que estão em contradição com expectativas surgidas ao mesmo tempo ou também com as estruturas de expectativas experimentadas e assumidas no passado. A libido sexual, que orienta a prática da pedofilia, incompatível com a "regra" imposta pela vivência clerical,

6 "Despite its wealth of information about human beings, their universe, and their God, the Bible is not intended to be a psychology text-book. (...) Of course, the Bible does not tell us about issues such as the biological basis of depression, the effect of accurate empathy, the lifelong devastation of emotional or physical abuse, the means by which people learn, the developmental stages of infancy, the fine points of conflict resolution, or the ways to treat dyslexia or paranoia." 
pode ser considerada, conforme acredita Kiyan (2005), uma situação crítica, tal como menciona Habermas.

A postura de reafirmação de um lugar e função aprazível para o clérigo católico é arquitetada pelas instâncias léxicoatitudinais de apreciação, em consonância com a expectativa do produtor sobre aqueles que denunciam ou acusam a prática sexual com menores pelos membros da Igreja. Essa observação é possível tendo em vista o julgamento de propriedade instanciado pela lexia "acusado" com a qual se avaliam principalmente os padres denunciados. Ao identificálos dessa maneira, o produtor admite e legitima o acusador, com todos os significados potencialmente negativos no meio religioso, que o termo acarreta.

O julgamento de propriedade diz respeito ao comportamento legal de um ator social, o que impugna, entre outras questões, o quão ético é esse ator (MARTIN; WHITE, 2005, p.52). A dimensão dessa atitude em que o domínio da ética aparece, abarca o campo das relações sociais mediadas, explícita ou implicitamente, por códigos de prescrições e proibições, por padrões de legitimação das condutas. De acordo com Eggins e Slade (1997, p.131), avaliações desse tipo evidenciam, especialmente por meio de unidades léxicas, o inadimplemento ou o cumprimento de regras de um sistema postas como necessidades sociais. 
O inadimplemento evidenciado com a atitude de acusar, e que faz com que o delator seja julgado negativamente pelo produtor, deve ser visto não como uma não ação, mas como uma ação reprovável, diabólica e não aconselhável à prática cristã. A interpretação que se faz toma como base tanto a etimologia do latim accusare - que remete a queixar-se - quanto o tratamento específico dado ao acusador no âmbito religioso.

Cumpre aduzir que "acusador", previsto por meio da forma "acusado" e na nominalização "acusação" em 92\% das instâncias atitudinais capazes de identificar o delator dos abusos sexuais - exemplo (C) - dimana do grego diabolos, no latim diabolôs - denotativo de intrigante, cujo exercício comum é a de inimizar com intrigas. Faz menção ainda à diaballein que prenuncia "atacar, acusar falsamente", literalmente "lançar através", de dia, "através", mais ballein, "jogar, lançar, atirar" (cf. SARAIVA, 1993).

Segundo Kelly (2008), quem tem pesquisado a figura literária do diabo nas Escrituras, este permanece na posição de acusador celestial dos humanos. Ele tem continuado a exercer essa função desde o presente e continuará no futuro, adicionando cristãos à sua lista de acusados.

Isso permite averiguar a transferência de culpa e reprovação que faz o produtor que advoga e arquiteta 
discursivamente a lidimidade do clérigo denunciado e, por conseguinte, o despudor do denunciante, identificado dessa forma em somente $8 \%$ das ocorrências - exemplo (D).

(C) O clérigo acusado goza da presunção de inocência até prova contrária, mesmo se o Bispo, com cautela, possa limitar o exercício do ministério, enquanto espera que se esclareçam as acusações.

(D) Os Bispos devem assegurar todo esforço no tratamento dos casos de eventuais abusos que porventura lhes sejam denunciados de acordo com a disciplina canônica e civil, no respeito dos direitos de todas as partes.

Em (D), a instância léxico-atitudinal de julgamento/ propriedade "denunciados" representa, como já indicado, uma maneira pouco frequente de identificação do delator e consequentemente do delatado. Diferentemente do que se reconhece na denotação negativa da utilização de "acusado" e "acusações" em (A), "denunciado" implica a ação estimada, no âmbito da tradição cristã, de anunciar, trazer boas novas. Segundo Saraiva (1993) a etimologia desse termo acusa a primeira conjugação no latim de denuntiare, cujo significado é o de anunciar, proclamar, fazer conhecer. O autor faz um levantamento dos registros que expressam diferentes usos do termo: 
Denuntiator, oris, s. ap. m. Inscr. O encarregado da polícia d'um bairro (...) Denuntio ou Denuncio, as, etc., are, v. trans. $1^{\circ}$ Anunciar, declarar, fazer saber, constar, advertir, avisar, pressagiar, prognosticar; 2ㅇ Citar, recorrer à autoridade; 3ㅇ Mandar, ordenar. 10 Denuntiare bellum. Cic. Fazer declaração de guerra. Denuntiavit populo collegam pugnasse. Cic. Anunciou ao povo que o seu colega tinha dado uma batalha. Denuntiare alicui ut...Caes. - ne...LIV. Avisar alguém que...; - que não... Denuntiavit abiret Ostiam. SUET. Declarou-lhe que se fosse para Ostia. Denuntiare coedem Coesari. SUET. Avisar Cesar de o quererem matar (...) hiemem asperam. PLIN. Pressagiar um inverno rigoroso (...) (SARAIVA, 1993, p.355, sic, grifo nosso)

Quaisquer usos que se observem com os respectivos exemplos, a cline de avaliação sobre o agente da ação, ou seja, o grau entre a positividade e a negatividade em que a opinião é lexicalmente expressa, tende ao positivo. Houaiss e Villar (2001, p.940) acrescenta a esses significados, com base na etimologia denunctio, revelar, evidenciar e levar ao conhecimento. O denunciador, enquanto o que revela e leva ao conhecimento, desperta, segundo Cozzens (2001, p.22), "uma ânsia muitas vezes indefinida, mas muito real de uma vida mais profunda do espírito, de uma extática união com Deus". 
Ainda em (D), a apreciação/valoração de relevância instanciada pelo epíteto "eventuais" corrobora o lugar aprazível com o qual o produtor busca associar o clérigo envolvido em casos de pedofilia, uma vez que atenua a assiduidade do delito clerical, pressupondo-o como casual, fortuito e acidental.

\section{CONSIDERAÇÕES FINAIS}

A identificação, o resumo e a interpretação das instâncias léxico-avaliativas que apontam o posicionamento afetivo, ético e estético do produtor de Carta Circular para ajudar as conferências episcopais na preparação de linhas diretrizes no tratamento dos casos de abuso sexual contra menores por parte de clérigos permitiu uma análise profícua sobre o modo como, em língua portuguesa, responde a Igreja às delações recebidas a partir dessa relação entre léxico e avaliação.

Reconhece-se, a partir dessa relação, a dinâmica da língua portuguesa, assim como se dá em qualquer outra. Essa dinâmica concentra-se, em especial no nível lexical, enquanto um sistema aberto propício a constantes ampliações. O léxico, desse modo, demonstra mais claramente a maneira como as pessoas de uma determinada cultura avaliam a realidade, os acontecimentos, e também as polêmicas sociais, como é o envolvimento de clérigos em casos de pedofilia. 
Com evidência, o primeiro aspecto que se depreende da investigação realizada no texto supracitado é a predominância das instâncias léxico-atitudinais do tipo apreciação/valoração. Por uso delas, o produtor pressupõe a resolução da Igreja em assistir, espiritual e psicologicamente, as vítimas de abuso sexual.

Essa resolução, que obviamente se estende aos clérigos na forma de instâncias do tipo julgamento de capacidade, os recontextualizam como quem assiste, tranquiliza e apascenta; não aqueles que coagem e abusam. Tal recontextualização encontra-se, conforme Cozzens (2001, p.21), consoante ao lugar que o clérigo ocupa na sociedade ocidental. $\mathrm{O}$ autor afirma que

Mesmo em nossa cultura secular pósmoderna, o colarinho e o terno preto podem evocar lembranças da suave alegria e da presença tranquilizadora desde muito associada aos padres paroquiais (2001, p.21).

As expectativas do produtor sobre aqueles que denunciam ou acusam a prática sexual com menores pelos membros da Igreja são instanciadas por julgamentos de propriedade. $\mathrm{O}$ julgamento de propriedade diz respeito ao comportamento legal de um ator social, o que impugna, entre outras questões, o quão ético é esse ator.

Ao assim agir, o produtor advoga e arquiteta discursivamente a lidimidade do clérigo em suspeita e, 
por conseguinte, o despudor do delator. Esclarece essa posição, o uso amiúde da lexia "acusado" em detrimento do uso incomum de "denunciado". O primeiro uso dimana do latim accusare, é significado do grego diabolos, do latim diabolus- denotativo de intrigante, cujo exercício comum é a de inimizar com intrigas. O segundo, preterido pelo produtor, ao identificar o denunciador, tem como base etimológica denuntiator que significa anunciar, revelar, trazer ao conhecimento e, dentro do âmbito católico, pode ser associado ao sacerdote que se encontra próximo de Deus.

Por fim, o produtor atenua a assiduidade do delito clerical, pressupondo-o como casual, fortuito e acidental, ao recorrer ao epíteto "eventuais", classificado como apreciação/ valoração de relevância, nas vezes que se refere à possível prática e confirmação do envolvimento de um clérigo em casos de abuso sexual.

\section{REFERÊNCIAS}

CARTER, R. (1987) Vocabulary: Applied Linguistic Perspectives. London: Allen \& Unwin.

BIDERMAN, M. (1996) Léxico e vocabulário fundamental. Alfa. São Paulo: UNESP, p.27-46.

BIDERMAN, M. (2001) Introdução: as ciências do léxico. In: OLIVEIRA, A; ISQUERDO, A. As ciências do léxico: lexicologia, lexicografia e terminologia. 2ed. Campo Grande: Ed. da UFMS, p.13-22. 
BIDERMAN, M. (2001a) Fundamentos de lexicologia. In: . Teoria Linguística (teoria lexical e linguística computacional). São Paulo: Martins Fontes, p.97-203.

COLLINS, G. (2000) An Integration View. Psychology \& Christianity. Downers Grove: InterVarsity Press, p.103-129.

COZZENS, D. (2001) A face mutante do sacerdócio. São Paulo: Loyola.

DAMASIO, A. (1994) Descartes' error: emotion, reason and the human brain. New York: Avon.

EGGINS, S. \& SLADE, D. (1997) Analysing casual conversation. London: Cassel.

FIRTH, J. (1957) Papers in Linguistics 1934-1951. London: Oxford University Press.

GEORGAKOPOULOU, A. \& GOUTSOS, D. (1997) Discourse Analysis: an introduction, Edinburgh: Edinburgh University Press.

HABERMAS, J. (1983) Para a reconstrução do materialismo histórico. São Paulo: Brasiliense.

HALLIDAY, M. A. K. (1994) An introduction to functional grammar. London: Melbourne Auckland.

HOEY, M. (1983) On the Surface of Discourse. London: Allen and Unwin.

HOUAISS, A. \& VILLAR, M. (2001) Dicionário Houaiss da língua portuguesa. Rio de Janeiro: Editora Objetiva.

HUNSTON, S. \& THOMPSON, G. (2003) "Evaluation: An introduction". In _-____. Evaluation in text: Authorial stance and the construction of discourse. New York: Oxford University Press, p.1-26.

IKEDA, S. (2006) "A crypo-argumentação e a construção do discurso estratégico". In Estudos Linguísticos XXXV, p.1877-1886.

KELLY, H. (2008) Satã - uma biografia. Rio de Janeiro: Editora Globo.

KIYAN, A. (2005) A identidade do sacerdote católico: um estudo sobre o celibato e a política de identidade da Igreja Católica. São Paulo: Pontifícia Universidade Católica de São Paulo. 
MACARTHUR, J. \& MACK, W. (1994) Introduction to Biblical Counseling. Dallas: Word.

MACKEN-HORARIK, M. (2003) Appraisal and special instructiveness of narrative. Text 23 (2). In Special edition on appraisal. Sydney: Text, p.285312.

MALINOWSKI, B. (1923) "The problem of meaning in primitive languages". In: Ogden, C. \& Richards, L. (eds.) The meaning of meaning. London: University of Cambridge, p.451-510.

MARTIN, J. (2003) "Beyond Exchange: Appraisal Systems in English". In: HUSTON, S. \& THOMPSON, G. (eds), Evaluation in text: Authorial stance and the construction of discourse. New York: Oxford University Press, p.142-175.

MARTIN, J. \& ROSE, D. (2003) Working with discourse: meaning beyond the clause. New York: Continuun.

MARTIN, J. \& WHITE, P. (2005) The language of evaluation: appraisal in English. London: Palgrave Macmillan.

SARAIVA, F. (1993) Novíssimo Dicionário Latino-português: Etimológico, prosódico, histórico, geográfico, mitológico, biográfico, etc, Rio de Janeiro: Nova Edição.

VIAN JUNIOR, O. (2007) O sistema de avaliatividade e os recursos para gradação em língua portuguesa: questões terminológicas e de instanciação. Revista Delta, p.99-129.

Alex Luis Santos. Doutorando na Universidade Federal de Minas Gerais (UFMG) em Estudos Linguísticos. Mestre em Letras na Universidade Federal de São João del-Rei. Atua principalmente nos seguintes temas: Avaliação na linguagem, Análise de Discurso Crítica, Linguística SistêmicoFuncional e Gramática do design Visual. Contato: alxlouis@hotmail.com

Cláudio Márcio do Carmo. Professor Adjunto IV da Universidade Federal de São João del-Rei. Pós-doutor em Antropologia (USP, 2012) Doutor em Linguística Aplicada (UFMG, 2005). Estudos com ênfase na Teoria e Análise Linguística e Linguística Aplicada. Temas privilegiados: cultura 
e produção de sentido, Linguística Sistêmico-Funcional, Linguística de Corpus, Sistema de Avaliatividade, Representação de Atores Sociais, Semiótica Social, Multimodalidade, Análise (Crítica) do Discurso e estudos lexicais. Contato: claudius@ufsj.edu.br

Recebido em 03 de junho de 2014. Aprovado em 22 de setembro de 2014. 


\section{ANEXO}

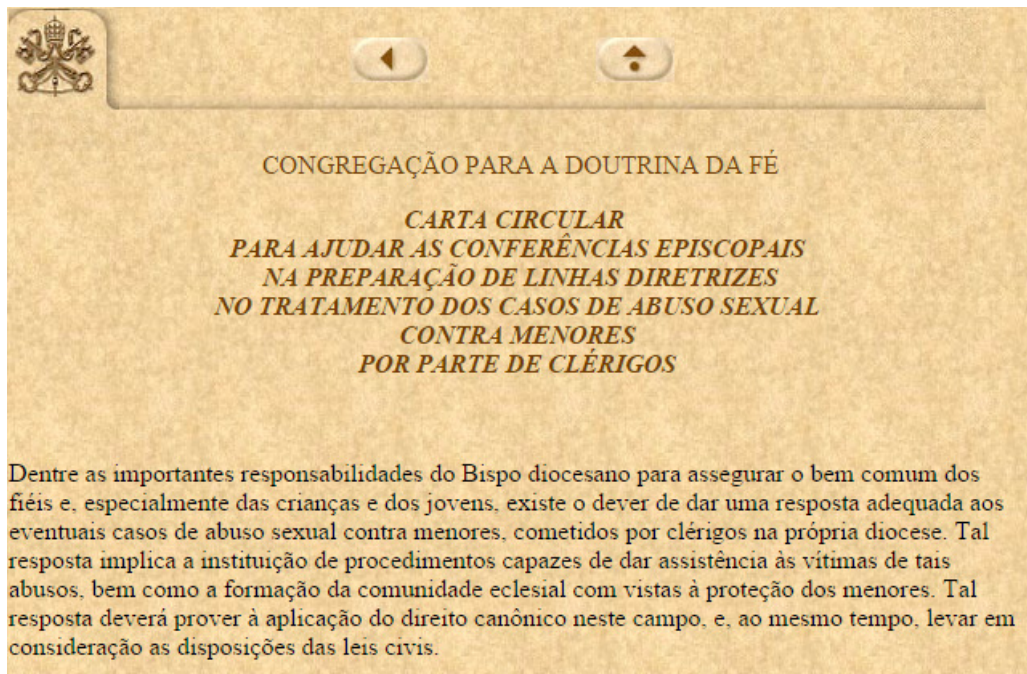

I.

Apectos gerais

\section{a) As vítimas do abuso sexual:}

A Igreja, na pessoa do Bispo ou de um seu delegado, deve se mostrar pronta para ouvir as vítimas e os seus familiares e para se empenhar na sua assistência espiritual e psicológica. No decorrer das

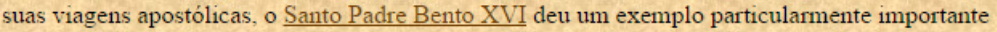
com a sua disposição para encontrar e ouvir as vítimas de abuso sexual. Por ocasião destes encontros, o Santo Padre quis se dirigir às vítimas com palavras de compaixão e de apoio, como aquelas que se encontram na sua Carta Pastoral aos Católicos da Irlanda (n. 6): "Sofrestes tremendamente e por isto sinto profundo desgosto. Sei que nada pode cancelar o mal que suportastes. Foi traida a vossa confiança e violada a vossa dignidade."

\section{b) A proteção dos menores:}

Em algumas nações foram lançados, em âmbito eclesiástico, programas educativos de prevenção, a fim de assegurar "ambientes seguros" para os menores. Tais programas tentam ajudar os pais, e também os operadores pastorais ou escolásticos, a reconhecer os sinais do abuso sexual e a adotar as medidas adequadas. Os supracitados programas mereceram amiúde um reconhecimento como modelos na luta para eliminar os casos de abuso sexual contra menores nas sociedades hodiernas.

\section{c) A formação dos futuros sacerdotes e religiosos}

O Papa João Paulo II dizia no ano de 2002: "No sacerdócio e na vida religiosa não existe lugar para quem poderia fazer mal aos jovens" (n. 3, Discurso aos Cardeais americanos. 23 de abril de 2002). Estas palavras chamam à atenção para a responsabilidade especifica dos Bispos, dos Superiores Maiores e daqueles que são responsáveis pelos futuros sacerdotes e religiosos. As indicações dadas na Exortação Apostólica Pastores Dabo Vobis, bem como as instruções dos Dicastérios competentes da Santa Sé, possuem uma importância sempre crescente com vistas a um correto discernimento vocacional e a uma formação humana e espiritual sadia dos candidatos. Em 
particular façam-se esforços de sorte que os candidatos apreciem a castidade, o celibato e a paternidade espiritual do clérigo e que possam aprofundar o conhecimento da disciplina da Igreja sobre o assunto. Indicações mais especificas podem ser integradas nos programas formativos dos seminários e das casas de formação previstas na respectiva Ratio Institutionis Sacerdotalis de cada nação e Instituto de Vida Consagrada e Sociedade de Vida Apostólica.

Uma diligência especial deve ser ademais reservada à indispensável troca de informações acerca daqueles candidatos ao sacerdócio ou à vida religiosa que são transferidos de um seminário a outro, de uma a outra Diocese ou de Institutos religosos a Dioceses.

\section{d) $O$ acompanhamento dos sacerdotes}

1. O Bispo tem o dever de tratar a todos os seus sacerdotes como pai e irmão. Além disso, o Bispo deve providenciar com atenção especial à formação permanente do clero, sobretudo nos primeiros anos seguintes à sagrada Ordenação, valorizando a importância da oração e do mútuo apoio na fraternidade sacerdotal. Os sacerdotes devem ser informados sobre o dano provocado por um clérigo à vítima de abuso sexual e sobre a própria responsabilidade diante da legislação canônica e civil, como também a reconhecer os sinais de eventuais abusos perpetrados contra menores;

2. Os Bispos devem assegurar todo esforço no tratamento dos casos de eventuais abusos que porventura lhes sejam denunciados de acordo com a disciplina canônica e civil, no respeito dos direitos de todas as partes;

3. O clérigo acusado goza da presunção de inocência até prova contrária, mesmo se o Bispo, com cautela, pode limitar o exercicio do ministério, enquanto espera que se esclareçam as acusações. Em caso de inocência, não se poupem esforços para reabilitar a boa fama do clérigo acusado injustamente.

\section{e) A cooperação com as autoridades civis}

O abuso sexual de menores não é só um delito canônico, mas também um crime perseguido pela autoridade civil. Se bem que as relações com as autoridades civis sejam diferentes nos diversos paises, é contudo importante cooperar com elas no âmbito das respectivas competências. Em particular se seguirão sempre as prescrições das leis civis no que toca o remeter os crimes às autoridades competentes, sem prejudicar o foro interno sacramental. É evidente que esta colaboração não se refere só aos casos de abuso cometidos por clérigos, mas diz respeito também aos casos de abuso que implicam o pessoal religioso ou leigo que trabalha nas estruturas eclesiásticas.

\section{II.}

\section{Breve relatório da legislação canônica em vigor relativa ao delito de abuso sexual de menores perpretado por um clérigo}

No dia 30 de abril de 2001, o Papa João Paulo II promulgou o Motu Própio Sacramentorum Sanctitatis Tutela (SST), com o qual se inseriu o abuso sexual de um menor perpetrado por um clérigo no elenco de delicta graviora, reservado à Congregação para a Doutrina da Fé (CDF). A prescrição de um tal delito foi fixada em 10 anos a partir do $18^{\circ}$ aniversário da vítima. A legislação do Motu Próprio vale tanto para os clérigos latinos quanto para os clérigos orientais, igualmente para o clero diocesano como para o religioso. 
Em 2003, o então Prefeito da CDF, o Cardeal Ratzinger, obteve de João Paulo II a concessão de algumas faculdades especiais para oferecer maior flexibilidade nos processos penais para os casos de delicta graviora, dentre os quais o uso do processo penal administrativo e o pedido da demissão ex officio nos casos mais graves. Estas faculdades foram integradas na revisão do Motu Próprio

aprovada pelo Santo Padre Bento XVI aos 21 de maio de 2010. Segundo as novas normas a prescrição é de 20 anos, os quais nos casos de abuso de menores se calculam a partir do $18^{\circ}$ aniversário da vítima. $\mathrm{A} C \mathrm{CDF}$ pode eventualmente derrogar às prescrições em casos particulares. Especificou-se também o delito canônico da aquisição, detenção ou divulgação de material pedopornográfico.

A responsabilidade de tratar os casos de abuso sexual contra menores é, num primeiro momento, dos Bispos ou dos Superiores Maiores. Se a acusação parecer verossímil, o Bispo, o Superior Maior ou o seu delegado devem proceder a uma inquisição preliminar de acordo com os cân. 1717 do CIC, 1468 CCEO e o art. 16 SST

Se a acusação for considerada crivel - digna de crédito, pede-se que o caso seja remetido à CDF. Uma vez estudado o caso, a CDF indicará ao Bispo ou al Superior Maior os ulteriores passos a serem dados. Ao mesmo tempo, a CDF oferecerá uma diretriz para assegurar as medidas apropriadas, seja grantindo um procedimento justo aos clérigos acusados, no respeito do seu direito fundamental à defesa, seja tutelando o bem da Igreja, inclusive o bem das vítimas. É útil recordar que normalmente a imposição de uma pena perpétua, como a dimissio do estado clerical requer um processo penal judicial. De acordo com o Direito Canônico (cf. can. 1342 CIC) os Ordinários não podem decretar penas perpétuas por decretos extra-judiciários; para tanto devem se dirigir à $\mathrm{CDF}$, à qual compete o juizo definitivo a respeito da culpabilidade e da eventual inidoneidade do clérigo para o ministério, bem como a consequente imposição da pena perpétua (SST Art. 21, § 2).

As medidas canônicas aplicadas contra um clérigo reconhecido culpado de abuso sexual de um menor são geralmente de dois tipos: 1) medidas que restringem o ministério público de modo completo ou pelo menos excluindo os contatos com menores. Tais medidas podem ser acompanhadas por um preceito penal; 2) penas eclesiásticas, dentre as quais a mais grave é a dimissio do estado clerical.

Em alguns casos, prévio pedido do próprio clérigo, pode-se conceder a dispensa, pro bono Ecclesiae das obrigações inerentes ao estado clerical, inclusive do celibato.

A inquisição preliminar e todo o processo devem se desenvolver com o devido respeito a fim de proteger a discreção em torno às pessoas envolvidas, e com a devida atenção à sua reputação.

Ao menos que existam razões graves em contrário, o clérigo acusado dever ser informado da acusação apresentada, a fím de que the seja dada a possibilidade de responder à mesma, antes de se transmitir um caso à CDF. A prudência do Bispo ou do Superior Maior decidirá qual informação deva ser comunicada al acusado durante a inquisição preliminar.

Compete ao Bispo ou ao Superior Maior prover ao bem comum determinando quais medidas de precaução previstas pelo cân. 1722 CIC e pelo cân. 1473 CCEO devam ser impostas. De acordo com o art. 19 SST, isto se faz depois de começada a inquisição preliminar.

Recorda-se finalmente que se alguma Conferência Episcopal, excetuado o caso de uma aprovação da Santa Sé, julgue por bem dar normas específicas, tal legislação particular dever ser considerada como um complemento à legislação universal e não como substituição desta. A legislação particular dever portanto harmonizar-se com o CIC/CCEO, bem como com o Motu Próprio Sacramentorum Sanctitatis Tutela (30 de abril de 2001) como foi atualizado aos 21 de maio de 2010. Se a Conferência Episcopal decidir estabelecer normas vinculantes, será necessário requerer a recognitio aos Dicastérios competentes da Cúria Romana. 


\section{Indicações aos Ordinários sobre o modo de proceder}

As linhas diretrizes preparadas pela Conferência Episcopal deveriam fornecer orientações aos

Bispos diocesanos e aos Superiores Maiores no caso em que fossem informados de possiveis (presunti) abusos sexuais contra menores perpetrados por clérigos presentes no território da sua jurisdição. Tais linhas diretrizes devem levar em conta as seguintes considerações:

a.) o conceito de "abuso sexual contra menores" deve coincidir com a definição do Motu Próprio SST art. 6 ("o delito contra o sexto mandamento do Decálogo cometido por um clérigo com um menor de dezoito anos"), bem como com a praxe interpretativa e a jurisprudência da Congregação para a Doutrina da Fé, levando em consideração as leis civis do Pais:

b.) a pessoa que denuncia o delito dever ser tratada com respeito. Nos casos em que o abuso sexual esteja ligado com um outro delito contra a dignidade do sacramento da Penitência (SST, art. 4), o denunciante tem direito de exigir que o seu nome não seja comunicado ao sacerdote denunciado (SST, art. 24);

c.) as autoridades eclesiásticas devem se empenhar para oferecer assitência espiritual e psicológica às vítimas;

d.) o exame das acusações seja feito com o devido respeito do princípio de privacy e da boa fama das pessoas;

e.) ao menos que haja graves razões em contrário, já durante o exame prévio, o clérigo acusado seja informado das acusações para ter a possibilidade de responder às mesmas;

f.) os órgãos consultivos de vigilância e de discernimento dos casos particulares, previstos em alguns lugares, não devem substituir o discernimento e a potestas regiminis dos Bispos em particular;

g.) as linhas diretrizes devem levar em consideração a legislação do País da Conferência, especialmente no tocante à eventual obrigação de avisar as autoridades civis:

h.) seja assegurado em todos os momentos dos processos disciplinares ou penais um sustento justo e digno ao clérigo acusado;

i.) exclua-se o retorno o clérigo ao ministério público se o mesmo for perigoso para os menores ou escandaloso para a comunidade.

\section{Conclusão}

As linhas diretrizes preparadas pelas Conferências Episcopais entendem proteger os menores e ajudar as vítimas para encontrar assistência e reconciliação. As mesmas deverão indicar que a responsabilidade no tratamento dos delitos de abuso sexual de menores por parte dos clérigos compete em primeiro lugar ao Bispo diocesano. Por fim, as linhas diretrizes deverão levar a uma orientação comum no seio de uma Conferência Episcopal, ajudando a harmonizar do melhor modo os esforços dos Bispos em particular a fim de salvaguardar os menores.

Roma, da sede da Congregação para a Doutrina da Fé, 3 de Maio de 2011

\section{William Cardinale Levada Prefeito}

